\title{
CONTRIBUIÇÃO AO CONHECIMENTO DO VALOR NUTRITIVO DO PEIXE DE ÂGUA DOCE, Pimelodus clarias BLOCH (MANDI)*
}

\author{
MARILIA OETTERER DE ANDRADE** \\ URGEL DE ALMEIDA LIMA***
}

\begin{abstract}
RESUMO
Como os peixes vem sendo indicados como alimentos com um certo zrau de excelência quanto à composição protéica, mineral e vitamínica, os autores pretenderam com o presente trabalho, verificar parte do valor nutritivo do mandi, analisando: proteína, lípides, cinza, cálcio, fósforo total, fósforo inorgânico, ferro e vitamina A.

Com a tinalidade ainda de comparar os resultados obtidos para peixes "in natura" com as conservas, procedeu-se às determinações também de umidade, $\mathrm{pH}$ e cloreto de sódio.

Cada $100 \mathrm{~g}$ dessa espécie de peixe pode suplementar cerca de $28 \%$ das necessidades calóricas diárias, $12 \%$ de fósforo, $69 \%$ de ferro e $22 \%$ de vitamina $\mathrm{A}$.
\end{abstract}

\section{INTRODUÇÃO}

Estudando trinta e seis espécies de peixes de água doce, NATARAJAN \& SREENIVASAN (1961) verificaram que a composição química varia amplamente entre as espécies, entre indivíduos e de estação para estação do ano. Os autores encontraram teores de umidade entre 67,90 e $83,60 \%$, prote ina entre 13,50 e 19,40\%, lipides entre 0,17 e 10,10\% e cinza entre 0,81 e $1,95 \%$. Nos peixes analisados inteiros o teor de cinza atingiu até $5,14 \%$. A análise de cinza revelou 0,09 a $2,66 \%$ de cálcio, 4,10 a $14,90 \%$ de ferro e 0,37 a $2,40 \%$ de fósforo total. A variação de lípides e umidade foi grande dentro de uma mesma espécie e para exemplificar foi anotada a espécie Cirrhina cirrhosa na qual os lípides variaram de 0,27 a 10,10\% e a umidade de 67,90 a 80,20\%.

STANSBY (1951) cita dados de outros autores sobre os teores de minerais da parte comestível de sete espécies de peixes de mar e de uma espécie de peixe de lago, além de cinco espécies de salmões enlatados. Os autores encontraram para o arenque de lago (Leuchthys artidi) "in natura": 17,9\% de matéria seca, 0,0116\% de cálcio, 0,0172\% de magnésio e $0,1518 \%$ de fósforo inorgânico. Nos salmões a matéria seca variou de 27,3 a $33,2 \%$ e os minerais apresentaram os seguintes teores em porcentagem: cálcio de 0,1071 a 0,2492 ; magnésio de 0,0267 a 0,0299 ; fósforo inorgânico de 0,2778 a 0,3518 e ferro de 0,00074 a 0,00127 .

* Entregue para publicação em 29/12/1975. Parte da Tese de Mestrado apresentada pela autora ANDRADE, M.O. de (1975), para obtenção do título de Mestre em Ciência de Alimentos, na Faculdade de Ciências Farmacêuticas da USP.

** Bolsista da FAPESP.

** Departamento de Tecnologia Rural da ESALQ. 
Segundo CAUSERET (1962) podem ocorrer variações nos teores de fósforo total conforme a espécie de peixe, o que pode ser notado na cavala que apresenta de 330 a $740 \mathrm{mg} / 100 \mathrm{~g}$ e no linguado americano com $240 \mathrm{a} 410 \mathrm{mg} / 100 \mathrm{~g}$. 0 autor explica que estas variações estão relacionadas com o teor de cálcio na água (relação $\mathrm{Ca} / \mathrm{P}$ ), idade, sexo e maturidade sexual do animal. Como exemplo, no arenque a relação $\mathrm{Ca} / \mathrm{P}$ decresce de 3,6 para 1,3 de novembro a janeiro.

Em artigo sobre composição de diversas espécies de pescado, SANTOS (1972) indica os teores extremos de umidade encontrada nos peixes: $45 \%$ nas espécies gordas e $84 \%$ nas espécies magras. Para os sais minerais ele relaciona em mg/100 g: 42,0 de cálcio, 24,0 de magnésio, 212,0 de fósforo inorgânico, 24,80 de ferro, 0,170 de cobre e 0,013 de iodo.

A análise dos constituintes minerais de peixes da América do Sul, de acordo com CAUSERET (1962) revelou para cálcio, fósforo inorgânico e ferro em $\mathrm{mg} / 100 \mathrm{~g}$ e cinza em porcentagem, os seguintes resultados: "cherlo" (Azanthistium pictus), 131; 114; 0,6 e 1,53; "macheti" (Ethmidium chilcae), 186; 103; 3,0 e 1,44; "colo" (Paralonchurus peruanus), 109; 209; 1,2 e 1,19; "white pomfret" ( Stromateus sp.), 48; 102; e 4,3 (neste não foi determinada a porcentagem de cinza).

A análise de "ratfish" (Hydrolagus colliei), inteiro, revelou os seguintes resultados: umidade $69,60 \%$, proteína $11,60 \%$, uréia $1,22 \%$, nitrogênio amoniacal $0,05 \%$, uréia e nitrogênio amoniacal calculados como proteína 3,74\%, lípides $18,10 \%$ e cinza $1,20 \%$. De acordo com o trabalho "Analysis of British Columbia ratfish" (1953), o resultado para proteína sem a correlação para uréia daria $15,30 \%$.

Citando diversos autores, WINTON \& WINTON (1937) apresentam uma tabela de composição química de grande número de peixes de mar e de água doce. Para o bagre registram $64,1 \%$ de umidade, $14,4 \%$ de proteína, $20,6 \%$ de lípides e $0,9 \%$ de cinza. Observando-se todos os resultados da tabela, nota-se que a maior variação entre as espécies se verifica para lípides, chegando à relação $1: 8$. Na análise de cinza, os autores mostram os seguintes resultados para enguias : 0,055 e $0,056 \%$ de cálcio, 0,008 e $0,006 \%$ de ferro, 0,405 e $0,485 \%$ de fósforo total, 0,336 e 0,392\% de fração fosfórica solúvel em água e 0,046 e $0,036 \%$ da fração fosfórica solúvel em etanol. Quanto ao ferro, os autores citam valores de 0,36 a $0,93 \mathrm{mg} / 100 \mathrm{~g}$ de peso úmido, sendo 0,40 para o bacalhau, 0,36 para o bagre, 0,73 para a solha, 0,93 para o hipoglosso, 0,78 para a truta de lago e 0,42 para o "whitefish".

KHAWAJA (1966) analisou dezoito espécies de peixes de água doce e verificou que o teor de proteína variou de 10 a 19\% sobre a matéria úmida. A umidade que se situou entre 79 e $80 \%$ foi consequência da baixa porcentagem de matéria graxa. O teor de cinza, de 1,04 a 2,09\%, foi maior nos peixes jovens do que nos adultos. O teor de cálcio variou de 0,031 a $2,217 \%$ e o de fósforo total de 0,322 a $0,605 \%$.

CAMARGO et alii (1972) estudaram os teores de minerais dos seguintes peixes: corimbatá, mandiuva, piapara, dourado e piava. Os autores analisaram os filés. $O$ teor de cinza em $\mathrm{g} / 100 \mathrm{~g}$ variou de 0,877 na mandiuva a 1,126 na piapara. $O$ teor de fósforo total em $\mathrm{mg} / 100 \mathrm{~g}$, variou de 344,406 na piava a 498,830 no dourado. Para cálcio em $\mathrm{mg} / 100 \mathrm{~g}$ os autores encontraram 85,046 para mandiuva e 113,928 para a piapara. $\mathrm{O}$ teor de ferro em $\mathrm{mg} / 100 \mathrm{~g}$ variou de 1,364 para o dourado e 2,200 para a piapara. Os 
teores de fósforo total e ferro da mandiuva (Pimelodus clarias) foram $476,305 \mathrm{mg} / 100 \mathrm{~g}$ e $1,400 \mathrm{mg} / 100 \mathrm{~g}$.

SCHMIDT (1948) analisou o "whitefish" (Coregonus clupeaformis) das águas de lago e apresentou os resultados de umidade, proteína, lípides e cinza em porcentagem de diversas partes do peixe. Os resultados obtidos de toda a parte comestível foram: $79.00 ; 17,20 ; 2,34$ e 1,16 . Da pele retirada desta parte: 73,$70 ; 18,50 ; 7,33$ e 0,86 . Da cabeça: $73,60,13,80 ; 6,78$ e 5,69. Dos ossos, barbatanas, cauda e escamas: 68,50; 17,$70 ; 8,24$ e 6,41 . Das vísceras: 80,$20 ; 13,30 ; 5,56$ e 1,41 . O autor determinou o teor de vitamina A nos lípides constituintes do músculo e obteve 480 U.I./g.

JAFRI \& QASIM (1965) estudaram o fígado de vinte e quatro espécies de peixes de água doce distribuídas entre as carpas, bagres, "murrels", "feather-backs", mugens e enguias. Os resultados obtidos para umidade, proteína, lípides, cinza, carboidratos, fósforo, cálcio em porcentagem e ferro total $\mathrm{em} \mathrm{mg/100} \mathrm{g} \mathrm{foram:} 8.9$ a 14,2,0,5 a 11,9; 66,9 a 81,$5 ; 18,4$ a 33,$1 ; 1,8$ a 10,$5 ; 1,1$ a 1,$8 ; 0,3$ a 1,$1 ; 0,01$ a 0,05 e 21,9 a 47,5 , respectivamente.

PANAIOTOVA \& BAIL'OZOV (1962) analisaram catorze espécies de peixes de mar e de rio e encontraram de 16 a $18 \%$ de proteína e 1 a $15 \%$ de lípides. Na fração cinza, cerca de $1 \%$, encontraram de 0,0023 a $0,2100 \%$ de cálcio e de 0,023 a $0,297 \%$ de fósforo inorgânico.

As fêmeas de Pimelodus clarias das águas interiores do Estado do Rio Grande do Sul, analisadas por RIOS (1957a) no mês de setembro e com $22 \mathrm{~cm}$ de comprimento, acusaram $61,78 \%$ de umidade, $14,74 \%$ de proteína, $22,61 \%$ de lípides, $0,87 \%$ de cinza e $0.25 \%$ de fósforo inorgânico.

Segundo MAURICIO (1962) os peixes são ricos em vitamina A e D, principalmente nos lípides do fígado; também são regularmente providos de tiamina, riboflavina e niacina. Cerca de $100 \mathrm{~g}$ de peixe satisfazem metade das necessidades de proteínas animais e de niacina; $10 \%$ de vitamina A, D e tiamina e $15 \%$ das necessidades de riboflavina. $\mathrm{O}$ autor cita a composição química de quarenta e três espécies de peixes em relação à proteína, lípides, cálcio e fósforo inorgânico em g/100 g de músculo e em relação ao ferro expresso em $\mathrm{mg} / 100 \mathrm{~g}$. Entre os peixes relacionados encontram-se: o bagre com $18.90 ; 11,40 ; 0,02 ; 0,20$ e 0,60 ; a merluza con 14,$20 ; 16,00 ; 0,05 ; 0,15$ e 0,30 ; o salmăo com 22,$50 ; 13,40 ; 0,02 ; 0,30$ e 1,$30 ;$ a sardinha com 23,$00 ; 19,70: 0,02 ; 0.31$ e 0,20 , e o tubarão com 17,$90 ; 25,20 ; 0,01 ; 0,26$ e 1,00 sendo cada valor correspondente aos itens retrocitados.

RIOS (1957b) determinou os teores de vitamina A no óleo de fígado de alguns peixes Teleósteos e alguns Eslamobrânquios do Estado do Rio Grande do Sul, utilizando o método de Carr-Price. $\mathrm{O}$ autor analisou quinze espécies de peixe e obteve grande variação nos resultados. Encontrou desde 420 U.I. de vitamina A/g na abrótea (Urophycis brasilensis) até 105.000 U.I. de vitamina A/g no bagre (Netuna barbus).

Segundo STANSBY (1951) os lípides do fígado dos peixes são os mais ricos em vitamina $\mathrm{A}$, enquanto os lípides distribuídos pelo corpo normalmente são pobres nessa vitamina.

GOUVEIA et alii (1956) estudaram a composição química de quinze espécies de peixes das Costas da Angola e verificaram que as quantidades de vitamina A variaram 
de 2,3 a 11,3 U.I./100 g de músculo. Nas vísceras os teores de vitamina A são consideravelmente maiores, variando de 2.470 a 147.250 U.I./100 g de vísceras.

JUNKER (1963) analisou filés de arenques de diferentes procedências e encontrou os seguintes teores de vitamina A, em U.I./100 g de filé: 100 a 450 no arenque de "Fladen", 50 a 380 no arenque de "Gat" e "Doggerbank", 50 a 240 no arenque do Canar, 100 a 200 no arenque do Báltico e 50 a 200 no arenque da Noruega.

O tecido muscular dos peixes é, segundo CRUICKSHANK (1962), muito pobre em vitamina $A$, principalmente nos peixes magros que chegam a não apresentarem vitamina A. A autora cita os teores encontrados em várias publicações e dentre eles estão em U.I./100 g de carne "in natura": 5 nos eglefins, 170 nas carpas, 180 nas cavalas, 400 nas solhas, 40 a 240 nos arenques, 4500 nas enguias de água doce, zero nos salmões do Atlântico e zero a 600 nos salmões do Pacífico.

Os teores de vitamina $\mathrm{A}$ em várias espécies de peixes são citados por JACQUOT (1961) com base nos dados de Grangaud e os resultados para lípides e vitamina A, respectivamente, são os seguintes: o "sprat" com 3 g/100 g e 100 U.I./100 g, o arenque com $6 \mathrm{~g} / 100 \mathrm{~g}$ e 20 a 400 U.I./100 g, a cavala com $8 \mathrm{~g} / 100 \mathrm{~g}$ e 150 U.I./100 g, o salmão com $11 \mathrm{~g} / 100 \mathrm{~g}$ e 70 a 500 U.I./100 g e a lampréia com $13 \mathrm{~g} / 100 \mathrm{~g}$ e 180 U.I./ $100 \mathrm{~g}$ :

Os teores de vitamina A encontradas na carne branca e escura de peixes analisados por HIGASHI (1961), foram os seguintes, para as duas colorações de carne e em U.I./100 g de tecido muscular: 70 e 120 no salmão, 77 e 115 na cavala, 47 e 110 no "saury", 91 e 102 no "starry flounder" e 2.270 e 5.450 na enguia.

As formas de vitamina A contendo uma dupla ligação extra são designadas como vitamina $\mathrm{A}_{2}$ e são encontradas em grande proporção nos peixes de água doce. Essa afirmativa é de CHANEY \& ROSS (1966) que ainda indicam o peixe como a mais rica fonte de vitamina A.

YASAKA et alii (1973) determinaram os teores de vitamina $A\left(A_{1}, A_{2}, A_{1}\right.$-aldeído, $A_{2}$-aldeído e vitamina $A-C_{22}$ ) no óleo do fígado de cinco espécies de peixes brasileiros de água doce e encontraram os teores extremos de $0,42 \mathrm{~g} / 100 \mathrm{~g}$ de vitamina $\mathrm{A}$ para o Salminus maxillosus e $3,85 \mathrm{~g} / 100 \mathrm{~g}$ para o Leporinus copelandi. Os teores mais baixos foram para o Pimelodus clarias, $0,28 \mathrm{~g} / 100 \mathrm{~g}$ de vitamina $\mathrm{A}_{1}$ e para o Prochilodus scrofa, $0,76 \mathrm{~g} / 100 \mathrm{~g}$ de vitamina $\mathrm{A}_{2}, 0,13 \mathrm{~g} / 100 \mathrm{~g}$ de vitamina $\mathrm{A}_{1}$-aldeído, $0,13 \mathrm{~g} / 100 \mathrm{~g}$ de vitamina $A_{2}$-aldeído e $0,62 \mathrm{~g} / 100 \mathrm{~g}$ de vitamina $A-C_{22}$. Os teores mais altos foram todos encontrados em Salminus maxillosus, em g/100 g: $\mathrm{A}_{1}$ 0,76; $\mathrm{A}_{2} 3,85 ; \mathrm{A}_{1}$-aldeído 3,18; $\mathrm{A}_{2}$-aldeído 0,48 e $\mathrm{A}-\mathrm{C}_{22} 2,73$.

Para CRUICKSHANK (1962) os peixes Teleósteos de água doce diferem das espécies marinhas, por possuírem uma maior proporção de vitamina $\mathrm{A}_{2}$ do que de vitamina $\mathrm{A}_{1}$ nos seus tecidos; por exemplo, a truta marrom (Salmo fario) contém por g de músculo, $0,5 \mathrm{mg}$ de vitamina $\mathrm{A}_{2}$ e $0,25 \mathrm{mg}$ de vitamina $\mathrm{A}_{1}$. A autora afirma que o teor de vitamina $\mathrm{A}$ no fígado de peixes de água doce é muito variável e é maior nas espécies que se alimentam de crustáceos e moluscos do que nas que se alimentam de plâncton.

HIGASHI (1961) afirma que poucas publicaçð̄es foram feitas sobre o teor de vitamina A no tecido muscular de peixes e cita alguns trabalhos onde estão agrupadas várias 
espécies, conforme o maior ou menor teor dessa vitamina. Com teores de zero a 20 U.I./g de músculo estão classificados a carpa, o "smooth dogfish", a enguia do mar e a arraia; com 101 a 150 U.I./g estão o "hagfish", o "graymullet" e o salmão; com 1.000 a 5.000 U.I./g está a enguia de água doce.

De acordo com MANDELLI (1967), na carne de sardinha o teor médio de vitamina A é de 80 U.I./g e em outras espécies pode chegar a 10.000 U.I./g.

BLACK \& SCHWARTZ (1950) determinaram o teor de vitamina A nos lípides das sardinhas capturadas nas águas do sul da África e encontraram uma variação de 106 a 209 U.I. de vitamina A/g de lípides.

\section{MATERIAL E MÉTODOS}

\section{Matéria-prima}

A matéria-prima, constituída de peixes conhecidos por mandi, foi adquirida de pescadores às margens do rio Piracicaba, no município de Piracicaba, Estado de São Paulo.

Segundo STORER \& USINGER (1971), os mandis pertencem à classe Osteichthyes, subclasse Actinopterygii, ordem Cypriniformes e familia Siluridae. De acordo com GOMES \& MONTEIRO (1965) foram classificados como Pimelodus clarias por Bloch em 1795 e por Lacépède em 1803.

EIGENMANN \& EIGENMANN (1890), classiticaram os mandis de alguns rios da América do Sul como pertencentes à espécie Pimelodus clarias. RIBEIRO (1918), classificou a espécie de mandi, predominante no rio Piracicaba, como Pimelodus clarias.

Us mandis são peixes de couro; seu comprimento varia entre 20 e $45 \mathrm{~cm}$ e sua massa de $100 \mathrm{~g} \mathrm{a} 1 \mathrm{~kg}$, de acordo com mensurações feitas por MONTEIRO (1953). Os machos atingem $33 \mathrm{~cm}$ de comprimento e $550 \mathrm{~g}$, enquanto que as fêmeas alcançam $45 \mathrm{~cm}$ com cerca de $1 \mathrm{~kg}$, segundo citação de GOMES \& MONTEIRO (1965). No presente trabalho foram usados espécimes com 100 a $300 \mathrm{~g}$, recém-capturados.

\section{Métodos}

\section{Umidade}

Determinada por método gravimétrico, através da perda de massa por aquecimento a $105^{\circ} \mathrm{C}$ até massa constante, segundo LUDORFF (1963).

\section{Proteina}

Determinada pelo método de Kjeldahl, micro, segundo A.O.A.C. (1971).

\section{Lipides}

Determinados por método gravimétrico após extração por clorofórmio-metanol, de acordo com FOLCH et alii (1957). 


\section{Cinza}

Determinado por método gravimétrico, através da perda de massa, após incinceração a 5500C, segundo A.O.A.C. (1971).

\section{Cálcio}

Determinado por método colorimétrico segundo FERRO \& HAM (1957).

\section{Fósforo Total e Fósforo Inorgânico}

Determinado por método colorimétrico segundo NAKAMURA (1957).

\section{Ferro}

Determinado por método colorimétrico segundo CRAMER et alii (1950).

\section{Vitamina A} (1966).

Determinada pelo método colorimétrico de Carr-Price, de acordo com FREED

$\mathrm{pH}$

Determinado com potenciômetro Methrom E-350, com aproximação de 0,1, aferido com solução-tampão a 6,8, inserindo o eletrodo na carne moída e homogeneizada com água recém-destilada, na mesma proporção da massa da amostra utilizada.

\section{Cloreto de Sódio}

Determinado por método volumétrico de acordo com LUDORFF (1963).

\section{Amostragem}

As análises químicas dos mandis "in natura" foram feitas em amostras de 10 peixes com massa de 100 a $300 \mathrm{~g}$. Depois da evisceração e lavagem em água corrente, foi retirada a parte comestível com um corte da cabeça à cauda, rente à coluna vertebral. Da parte comestivel foram retirados as nadadeiras e a carne foi homogeneizada em liquidificador a $1.500 \mathrm{rpm}$ por 2 minutos. 


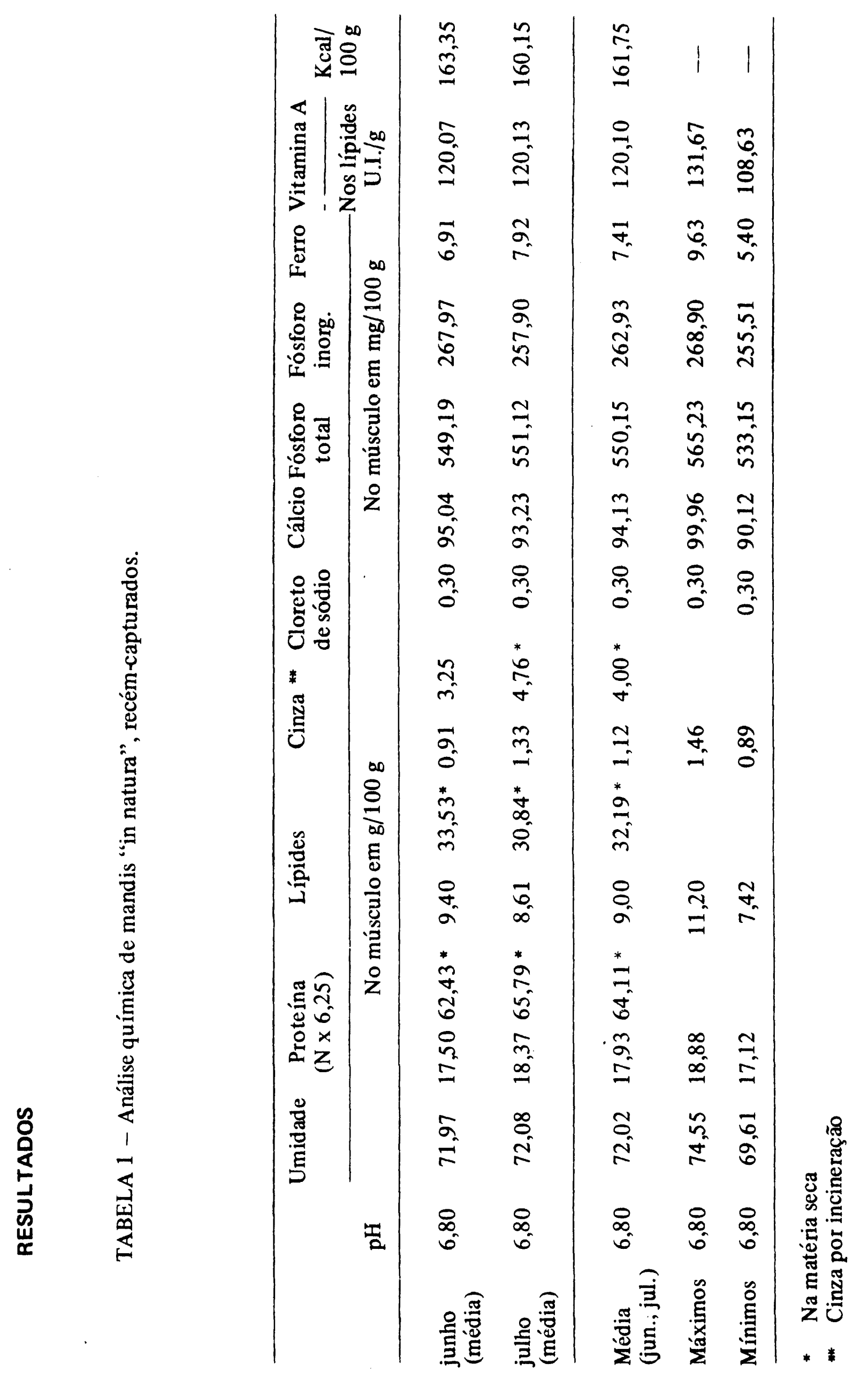




\section{DISCUSSÃO DOS RESULTADOS}

A Tabela 1 mostra, além da composição centesimal, os teores de cloreto de sódio, cálcio, fósforo total, fósforo inorgânico, ferro, vitamina $\mathrm{A}$, o valor do $\mathrm{pH}$ e as quilocalorias do peixe "in natura".

No processamento foram utilizados mandis de junho a julho porque o teor de lípides nesses meses se apresenta em seus níveis mínimos, de acordo com ANDRADE (1975). O excesso deste componente, segundo ANDRADE \& LIMA (1974), além de dificultar o manuseio, confere aspecto, aroma e sabor menos aceitáveis às conservas. Os teores de umidade, que nos meses de junho e julho foram 71,97 e $72,08 \mathrm{~g} / 100 \mathrm{~g}$, respectivamente, devem ser diminuídas com o pré-cozimento e secagem. Nesses meses, os peixes apresentaram a média de $17,93 \mathrm{~g} / 100 \mathrm{~g}$ de proteína, muito próxima da média anual de $17,92 \mathrm{~g} / 100 \mathrm{~g}$ e, em termos de matéria seca, nessa época ocorreram os teores máximos de proteína.

O teor de cloreto de sódio do mandi "in natura" foi $0,30 \mathrm{~g} / 100 \mathrm{~g}$. Resultado semelhante foi encontrado por LUDORFF (1963) em arenques in teiros capturados de janeiro a abril, mas teores superiores foram observados pelo mesmo autor, nos filés de arenques em outra época do ano.

A cinza do peixe "in natura" aumentou de $0,91 \mathrm{~g} / 100 \mathrm{~g}$, em junho, para 1,33 $\mathrm{g} / 100 \mathrm{~g}$ em julho, enquanto a umidade foi praticamente a mesma: de 71,97 e 72,08 $\mathrm{g} / 100 \mathrm{~g}$ para cada mês. Os resultados em matéria seca confirmam a variação na cinza para a qual se encontrou $3,25 \mathrm{~g} / 100 \mathrm{~g}$ em junho e $4,76 \mathrm{~g} / 100 \mathrm{~g}$ em julho.

O teor médio de cálcio dos peixes "in natura", em junho e julho, foi 94,23 $\mathrm{mg} / 100 \mathrm{~g}$. Este resultado está coerente com os encontrados por CAUSERET (1962), KHAWAJA (1966), NATARAJAN \& SREENIVASAN (1961), PANAIOTOVA \& BAIL'OZOV (1962) e STANSBY (1961) em várias espécies de peixes e por CAMARGO et alii (1972) no Pimelodus clarias. Teores mais baixos, em outras espécies, foram obtidos por alguns pesquisadores (MAURICIO, 1962; SANTOS, 1972 e WINTON \& WIN. TON, 1937).

Os teores médios de fósforo total e fósforo inorgânico dos mandis "in natura", na época de processamento, foram 550,15 e $262,92 \mathrm{mg} / 100 \mathrm{~g}$, respectivamente. Segundo CAUSERET (1962), o teor de fósforo em peixes pode variar com a espécie, com a idade, com o sexo, com a maturidade sexual, com a época do ano e com a relação $\mathrm{Ca} / \mathrm{P}$ da água. Os resultados obtidos, neste trabalho, para fósforo total foram concordantes com os de CAUSERET (1962), KHAWAJA (1966), NATARAJAN \& SREENIVASAN (1961) e WINTON \& WINTON (1937), mas foram mais elevados do que os encontrados por CAMARGO et alii (1972) no Pimelodus clarias. Os resultados obtidos para fósforo inorgânico estão condizentes com os encontrados em alguns trabalhos para outras espécies por MAURÍCIO (1962), PANAIOTOVA \& BAIL'OZOV (1962), STANSBY (1951) e RIOS (1957a) no Pimelodus clarias; mas se apresentam mais al tos do que os de CAUSERET (1962) e SANTOS (1972).

O teor médio de ferro na cinza dos mandis "in natura" nos meses de junho e julho foi $7,41 \mathrm{mg} / 100 \mathrm{~g}$. Este resultado está coerente com os encontrados por WINTON 
\& WINTON (1937) nas enguias. No entanto, a maioria dos autores obteve teores mais baixos do que os do presente trabalho, em outras espécies, citados por CAUSERET (1962), MAURICIO (1962), NATARAJAN \& SREENIVASAN (1961), SANTOS (1972), STANSBY (1951) e WINTON \& WINTON (1937). Para o Pimelodus clarias os teores de ferro encontrados por CAMARGO et alii (1972) também foram mais baixos.

Para a vitamina A do óleo do mandi foi encontrado o teor médio de 120,10 U.I./g de lípides o que corresponde a $1.080,90$ U.I./100 g de músculo. Este teor pode ser considerado elevado quando comparado com os obtidos por alguns autores em outros peixes (CAUSERET, 1962; GOUVEIA, 1956; JACQUOT, 1961 e JUNKER, 1956). Os trabalhos de CRUICKSHANK (1962), HIGASHI (1961) e MANDELLI (1967) mostram teores maiores e menores, conforme a espécie analisada. Teores semelhantes aos obtidos com o mandi foram encontrados por BLACK \& SCHWARTZ (1950) e HIGASHI (1961), mas existem também peixes mals ricos em vitamina $\mathrm{A}$, como os que foram analisados por CRUICKSHANK (1962), HIGASHI (1961) e SCHMIDT (1948). Segundo a bibliografia, o teor de vitamina A do óleo de fígado de peixes é muito mais eelevado do que o do músculo. Comparando os resultados deste trabalho, com os teores de vitamina $\mathrm{A}_{1}$ no óleo do fígado e os de vitamina $\mathrm{A}$ no músculo do Pimelodus clarias, encontrados por YASAKA et alii (1973), vê-se que no mandi, essa vitamina está aproximadamente oitenta vezes mais concentrada no fígado.

Para calcular o valor calórico de $100 \mathrm{~g}$ de carne de mandi, considerou-se a proteína multiplicada por 4,5 e os lípides multiplicados por 9,0 . Assim, o resultado obtido foi $161,75 \mathrm{kcal} / 100 \mathrm{~g}$ de músculo que correspondem a $28 \%$ das necessidades diárias de um indivíduo.

Os resultados em minerais e vitamina A foram comparados com as tabelas fornecidas pela "Recommended Dietary Allowances" publicadas pela Documenta Geigy General Practioner Series (1967), onde verificou-se que $100 \mathrm{~g}$ de carne de mandi podem suplementar cerca de $12 \%$ de fósforo total e $69 \%$ de ferro, além de $22 \%$ de vitamina $\mathrm{A}$.

\section{CONCLUSÕES}

Os mandis, nos meses de junho e julho, capturados para o processamento, apresentaram, na parte comestivel, teores médios de $72,02 \mathrm{~g} / 100 \mathrm{~g}$ de umidade; $17,93 \mathrm{~g} / 100 \mathrm{~g}$ de proteína; $9,00 \mathrm{~g} / 100 \mathrm{~g}$ de lípides; $1,12 \mathrm{~g} / 100 \mathrm{~g}$ de cinza; $94,13 \mathrm{mg} / 100 \mathrm{~g}$ de cálcio; $550,15 \mathrm{mg} / 100 \mathrm{~g}$ de fósforo total; $262,93 \mathrm{mg} / 100 \mathrm{~g}$ de fósforo inorgânico; 7,41 $\mathrm{mg} / 100 \mathrm{~g}$ de ferro; 120,10 U.I. de vitamina $\mathrm{A}$ por $\mathrm{g}$ de lípides; $0,30 \mathrm{~g} / 100 \mathrm{~g}$ de cloreto de sódio e $\mathrm{pH}$ de 6,80 . Cada $100 \mathrm{~g}$ de carne de mandi podem fornecer ao organismo, cerca de $28 \%$ das necessidades calóricas diárias, $12 \%$ de fósforo total, $69 \%$ de ferro e $22 \%$ de vitamina $\mathrm{A}$. 


\section{SUMMARY}

\section{STUDY OF SOME ASPECTS OF THE NUTRITIVE VALUE OF BRAZILIAN FRESH WATER FISH, Pimelodus clarias, BLOCH (MANDI)}

This work was carried out on. "mandi" (Pimelodus clarias Bloch) a specie of catfish from Piracicaba river, in São Paulo State, Brazil, with the purpose of knowing its chemical composition and some informations of its nutritional value.

The fishes picked out in June and July, showed the following composition of the edible part: moisture $72.02 \mathrm{~g} / 100 \mathrm{~g}$, protein $17.93 \mathrm{~g} / 100 \mathrm{~g}$, lipids $9.00 \mathrm{~g} / 100 \mathrm{~g}$, ash $1.12 \mathrm{~g} / 100 \mathrm{~g}$, calcium $94.13 \mathrm{mg} / 100 \mathrm{~g}$, total phosphorus $550.15 \mathrm{mg} / 100 \mathrm{~g}$, inorganic phosphorus $262.93 \mathrm{mg} / 100 \mathrm{~g}$, iron $7.41 \mathrm{mg} / 100 \mathrm{~g}$, sodium chloride $0.30 \mathrm{~g} / 100 \mathrm{~g}$, vitamin A 120.10 U.I./g lipids and $\mathrm{pH} 6.80$.

It was showed that each $100 \mathrm{~g}$ of the fish flesh can supply about $12 \%$ of total phosphorus, $69 \%$ of iron, $22 \%$ of vitamin $\mathrm{A}$ and $28 \%$ of the caloric daily needs.

\section{LITERATURA CITADA}

ANALYSIS of British Columbia ratfish., 1973. Prog. Rept. Pacific. Coast. Sta., Vancouver, 94:23. ANDRADE, M.O. de \& LIMA, U. de A., 1974. Aproveitamento tecnológico do mandi - Defumação. An. IV Jornada ci. Fac. Ciênc. Méd. Biol. Botucatu:48.

ANDRADE, M.O. de., 1975. Preparo, seleção, armazenamento e estudos químicos e sensoriais da conserva de mandi, Pimelodus clarias Bloch. São Paulo. 127 p. Tese (mestrado). F.C.F. USP.

ASSOCIATION OF OFFICIAL AGRICULTURAL CHEMISTS., 1971. Official and Tentative methods of analysis. 11th. ed. Washington, A.O.A.C., p.'295, 526 e 858.

BLACK, M.M. \& SCHWARTZ, H.M., 1950. South African products. XXX: Seasonal changes of the piichard. J. Sci. Food Agric., Londres, 1(6):182-5.

CAMARGO, L.A. de A. et alii, 1972. Teor de cálcio, ferro e fósforo em alguns peixes brasileiros de ágıa doce. R. Inst. Adolfo Lutz, São Paulo, 32:113-7.

CAUSERET, J., 1962. Fish as source of mineral nutrition. In: BORGSTROM, G. ed. - Fish as food, New York, Academic Press, v. 2. p. 211, 212, 221, 224.

CHANEY, M.S. \& ROSS, M.L., 1966. Nutrition. 7th. ed., Boston, Houghton Mifflin, p. 189, 457.

CRAMER, E.R. et alii, 1950. Teor mineral de alguns alimentos brasileiros. Subsídios para uma tabela nacional. Memória III. R. Nutr., Rio de Janeiro, 1(1):88-9.

CRUICKSHANK, E.M., 1962. Fat soluble vitamins. In: BORGSTROM, G., ed. - Fish as food. New York, Academic Press, v. 2, p. 187, 190, 191.

EIGENMANN, C.H. \& EIGENMANN, R.S., 1955. A revision of South American Nematognathi or cat-fishes. Occ. Pap. Cai. Acad. Sci., 1:509, 1890. Apud GOMES, A.L. \& MONTEIRO, F.P. - Estudo da população de peixes da represa da Estação Experimental de Biologia e Piscicultura em Pirassununga, SP, R. Biol. Mar, Valparaíso, 6(1/3):101.

FERRO, P.U.A.S. \& HAM, A.M., 1957. Colorimetric determination of calcium by chloranilic acid. II: A semimicro method with reduced precipitation time. Am. J. Clin. Path., Baltimore, 28(6).689-92. 
FOLCH, J. et alii, 1957. A simple method for the isolation and purification of total lipids from animal tissues. J. Biol. Chem., Baltimore, $226: 497-509$.

FREED, M., 1966. Methods of vitamin assay. 3rd. ed. London, Interscience. p. 70-9.

GOMES, A.L. \& MONTEIRO, F.P., 1965. Estudo da população total de peixes da represa da Estação Experimental de Biologia e Piscicultura em Pirassununga, SP. R. Biol. Mar., Valparaíso, $6(1 / 3): 101,124$.

GOUVEIA, A.J.A. et alii, 1956. Estudo químico de peixes da costa de Angola. I : Estudo analítico de algumas espécies das peixarias de Luanda. Garcia Orta, Lisboa, 4:531-55.

HIGASHI, H., 1961. Vitamins in fish withspecial reference to edible parts. In: BORGSTROM, G., ed. - Fish as food. New York, Academic Press, v.1, p. 422-3, 425.

JACQUOT, R., 1961. Organic constituents of fish and other aquatic foods. In: BORGSTROM, G., ed. - Fish as food. New York, Academic Press, v.1, p. 146-50.

JAFRI, A.K. \& QASIM, S.Z., 1965. Studies on the biochemical compositition of some freshwater fishes. II : liver. Fish Technol., Ernakulam, 11(2):163-9.

JUNKER, M., 1956. Vitamin A in fishen, krebsen und muscheln. Archiv f. Fischerei-wissens-chaft, 7(3):248-60. Apud LUDORFF, W. - El pescado y sus productos. (Trad.) Zaragoza, Acríbia, 1963. p. 40.

KHAWAJA, D.K., 1966. Biochemical composition of the muscle of some freshwater fishes during the prematurity phase. Fish Technol. Ernakulam, 3(2) 94-102.

LUDORFF, W., 1963. El pescado y sus productos. (Trad.). Zaragoza, Acríbia, p.34-5, 108, 117-8, $139,157,159$.

MANDELLI, M.Q., 1967. Pescado - valor nutritivo. R. nac. Pesca, Santos, 8(80) 9-11.

MAURICIO, H.V., 1962. Pesca e alimentação no Brasil - Pesca: sua importância alimentar. Arq. Bras. Nutr., Rio de Janeiro, 18(1-2):49-63.

MONTEIRO, F.P., 1953. A pesca no rio Piracicaba. Piracicaba, 76 p. Tese (doutoramento) ESALQUSP.

NAKAMURA, M., 1957. The series of chemical experiments. B. Chem. Soc. Jap., Toquio, 23.532.

NATARAJAN, V.M. \& SREENIVASAN, A., 1961. Proximate and mincral composition of freshwater fishes. Ind. J. Fish., Bhavanisagar, 8(2):422-9.

PANAIOTOVA, M. \& BAIL'OZOV, D., 1962. Composition of some sea and freshwater fishes. Akad. Nauk, Bulgaria, 2(2):113-9, 1960. Apud Chem. Abstr., Easton, 56.6429b.

RECOMMENDED Dietary Allowances, 1967. Nutritional value. Documenta Geigy General practitioner series. $40 \mathrm{p}$.

RIBEIRO, A. de M., 1951. Peixes. Rev. Museu Paulista, 10:730, 1918. Apud FOWLER, H.W. Os peixes de água doce do Brasil. Arq. Zool. Est. São Paulo, $6: 556$.

RIOS, E. de C., 1957a. Variação estacional da composição química do pescado. An. Assoc. Bras. Quím., Porto Alegre, 16(1-4):97-112.

RIOS, E. de C., 1957b. Vitamina A em peixes teleósteos. An. Assoc. Bras. Quím., Porto Alegre, $16(1-4): 113-5$.

SANTOS, E.S. dos., 1972. Composição da carne de pescado e sua importância na alimentação humana. Anu. Pesca. Supl. R. Nac. Pesca, Santos, p. 54-7.

SCHMIDT, P.J., 1948. Analysis of freshwater fishes from canadian interior provinces, Manitoba. Off. rech. pêch. Canadá (Pacific Progr. Rept. 75 p. 48-50).

STANSBY, M.E., 1951. Fish, shellfish and crustacea. In: JACOBS, M.B. - The chemistry and technology of food and food products. 2nd. ed. New York, Interscience, v.2, p. 9434. 
STORER, T.I. \& USINGER, R.L., 1971. Zoologia geral. São Paulo, Ed. USP. p. 564-84.

WINTON, A.L. \& WINTON, K.B., 1937. The structure and composition of foods. New York, John Wiley, v.3, p. 433, 435, 439-40, 442, 459, 461.

YASAKA, W.J. et alii., 1973. Vitamin A and related compounds in liver oil of Brazilian freshwater fish. J. Nutr. Sci. Vitaminol., Toquio, 19(5):369-73. 